\title{
Study on the Effect of Group Reciprocity Model in the Rehabilitation of Patients with Scoliosis
}

\author{
Yaqin Hu, Xia Chen*, Xinyi Guo \\ Faculty of Law, Southwest Petroleum University, Chengdu, China \\ Email: ${ }^{*}$ c1650822539@126.com
}

How to cite this paper: Hu, Y. Q., Chen, X., \& Guo, X. Y. (2021). Study on the Effect of Group Reciprocity Model in the Rehabilitation of Patients with Scoliosis. Open Journal of Social Sciences, 9, 16-25.

https://doi.org/10.4236/jss.2021.94002

Received: March 4, 2021

Accepted: April 3, 2021

Published: April 6, 2021

Copyright $\odot 2021$ by author(s) and Scientific Research Publishing Inc. This work is licensed under the Creative Commons Attribution International License (CC BY 4.0).

http://creativecommons.org/licenses/by/4.0/

\begin{abstract}
Scoliosis is a common spinal deformity in clinic, which has a serious impact on patients' daily life and aesthetics. The incidence of scoliosis patients in my country is $2 \%$. At present, scholars' attention to this issue has fluctuated. However, research articles mainly focus on pathological research. This article starts from the improvement of the patients' psychological conditions, through the assessment of the needs of the patients, and uses the group reciprocity model to carry out activities to enhance the client's social support to observe the rehabilitation effect.
\end{abstract}

\section{Keywords}

Group Reciprocity Model, Patients with Scoliosis, Effect Study

\section{Background}

\subsection{Physiological and Psychological Conditions of Patients with Scoliosis}

After patients with scoliosis are sick, the degree of scoliosis will affect the normal operation of their cardiopulmonary function, and they are prone to poor postures such as unequal length of lower limbs and coronal scoliosis. Due to changes in posture, patients are prone to feelings of inferiority, anxiety, and negativity. Among patients with idiopathic scoliosis, $90 \%$ are adolescents, and their inferiority complex and negative emotions are more obvious, resulting in less communication with others and low social integration. This negative emotion has a negative impact on the patient's subsequent treatment, is not conducive to the rehabilitation process (Ma, Xie, Zhang, Liu, \& Feng, 2016).

\subsection{Current Domestic Research on Patients with Scoliosis}

According to statistics published on CNKI related topics (Figure 1), the current 


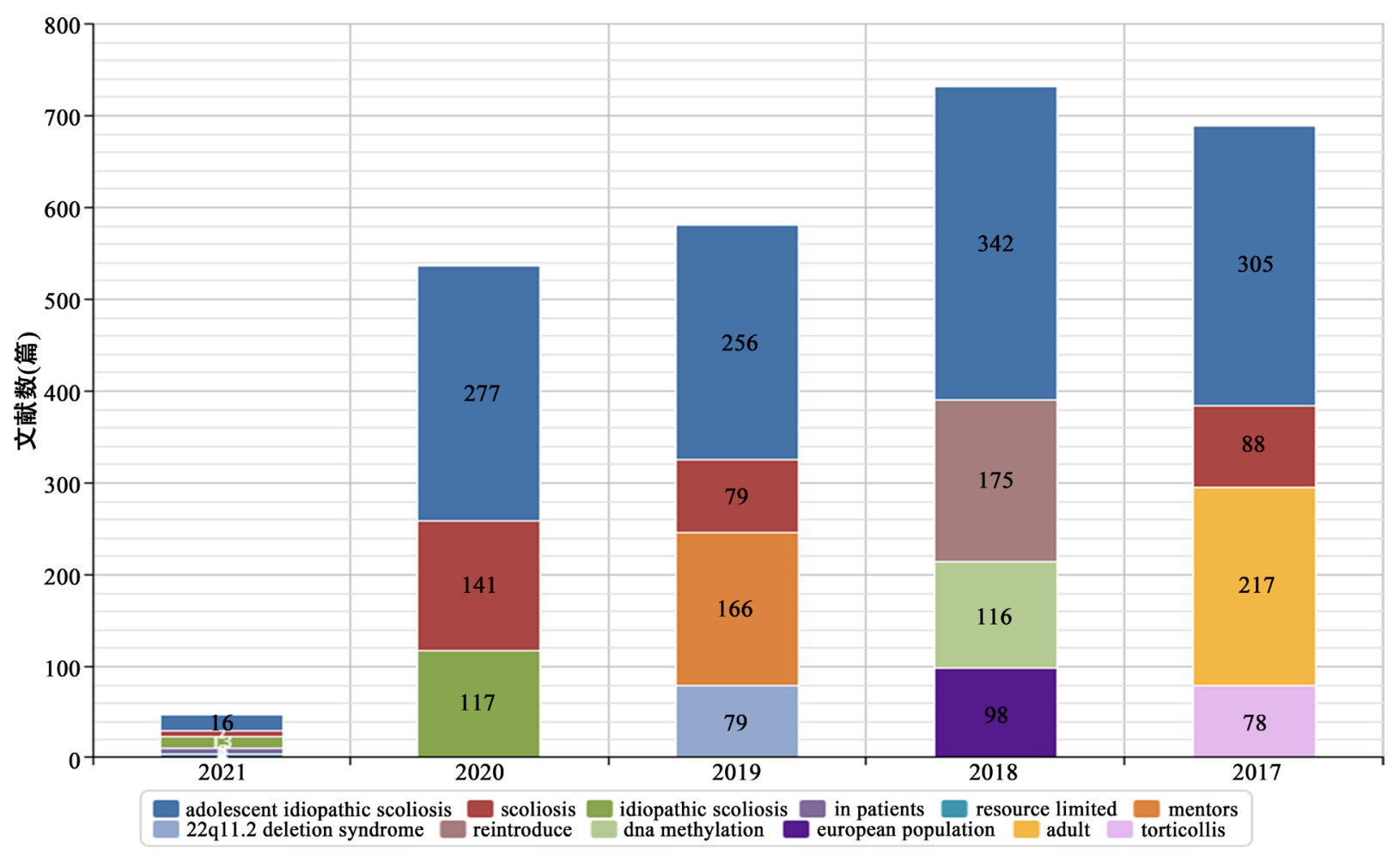

Figure 1. Trends in the publication of scoliosis topic articles.

domestic attention to scoliosis patients fluctuates, but the research direction of the thesis mainly focuses on the pathological condition of patients with scoliosis, and less attention is paid to the psychological status of patients and the impact of social factors on the rehabilitation process of patients

In the research on the factors affecting the rehabilitation process of patients with scoliosis, many scholars believe that the patient's psychological condition will affect the later treatment effect. Yunli Li scholars believe that the improvement of psychological factors will better promote rehabilitation (Li, 2019). Scholars such as Huizhen Hou, Xiaoliang Chai and other scholars believe that the patient's negative emotions will have a negative impact on the body, which is not conducive to the recovery of the patient (Hou, Chai, Li, \& Cai, 2017). Jiaquan Zhao and Weijun Zeng scholars use Rosenthal effect to carry out nursing intervention to improve patients' negative emotions, reduce patients' stress response, and promote better treatment of patients (Zhao \& Zeng, 2020). Many scholars also believe that patients' psychological and social factors will affect their recovery process. Fengna Zhao, Hongju Peng and other scholars have conducted research on patients' anxiety and influencing factors, and believe that patients' improvement of psychological and social support factors can improve their treatment effects and quality of life (Zhao, Peng, Huo, \& Dong, 2016). Shiwen Xue's research combined with the services and countermeasures of medical social workers, and concluded that patients' psychological and social health needs should be paid attention to, in order to reduce patient pressure and help patients recover (Xue, 2019). 


\subsection{The Effect of Group Reciprocity Model on Psychological and Social Support}

In recent years, the group reciprocity model has achieved good results in alleviating patient pressure, providing emotional counseling, and establishing social support networks. The group reciprocity model is to establish a support system between groups by paying attention to the relationship between individuals and society, so that individuals can obtain an "independent" work model from it.

This study focuses on the impact of psychological and social factors on the rehabilitation effect of patients with scoliosis, and tries to use the professional method of reciprocal groups to establish a support network among patients. Through the interactive and supportive features of the reciprocal group model, it helps the client get full communication, emotional counseling, and social integration in the group, and get out of the predicament from mutual assistance among members, so as to better recover. In the group, patients share their experience of adapting to the condition, relieve stress, and adjust their mood. Medical social workers play the role of enabler and coordinator, interact with patients together, help patients get out of psychological dilemma, and better adapt to the rehabilitation process.

\section{Research Content}

\subsection{Research Objects}

All patients with scoliosis in the Third People's Hospital of Chengdu.

\subsection{Research Methods}

Field research, controlled research, baseline measurement method.

\subsection{Research Goals and Objectives}

\section{Goals:}

By studying the effect of the social work reciprocity group model in patients with scoliosis, the project optimizes the rehabilitation environment, helps patients recover faster, and promotes the application of the reciprocity model in other fields, laying the foundation for follow-up research.

\section{Objectives:}

- Use questionnaires and structured interviews to investigate and understand the rehabilitation status of patients with scoliosis after participating in the reciprocal group model, and to understand the effect of the mutual assistance model in the rehabilitation process of patients with basal scoliosis.

- Use baseline comparison and other methods to evaluate the application effect of the reciprocal group model in the rehabilitation of patients with scoliosis.

- Understand the patient's rehabilitation status and the application effect of the reciprocal group, analyze and summarize the advantages and limitations of the reciprocal group model applied to the rehabilitation process of scoliosis patients. 
- An attempt was made in the field of medical social work to summarize the advantages and limitations of the reciprocal group model in the rehabilitation of patients with scoliosis.

\subsection{Problems to Be Solved}

- Optimize the rehabilitation environment-Regarding the environment created by the previous activities that are not suitable for the rehabilitation of patients, a reasonable reciprocal group plan is designed to optimize the rehabilitation environment for patients with scoliosis.

- The problem of matching between the model and the patient-Innovation the content of the reciprocal group social work mode and work methods, make it corresponds to the patients with scoliosis condition, avoid mutual group before mode existing in the "social work arranged, leadership activities" problem, solve social workers in reciprocal mode deviation problem, play a role in correcting social worker role in mutually mode is more of a good broker, mediator's role.

- Patient's recovery status-The baseline survey method is used to record the client's recovery status before and after participating in the group reciprocity mode, and to grasp the change of the client's recovery status by comparing the two recovery statuses.

- Adaptation to diseases and complications-The patient's maladjustment to the disease: The activities carried out in the reciprocity group provide a platform for patients to share experiences on how to adapt to the physical, psychological and social relations caused by the disease. Through the sharing of experiences of overcoming physical, psychological and social discomforts with other patients, we guide and encourage patients to change themselves to adapt to the disease.

- Lack of communication and mutual support between patients-Build an effective support system between patients: Through the development of reciprocal group activities, patients strengthen the interaction between patients, communicate with each other's conditions, and support each other in the activities, including helping each other physically for rehabilitation training, and comforting each other psychologically, encouraging and supporting each other.

\section{Theoretical Support}

\section{Social support network theory}

After the 1970s, social support has become a hot research field. In the field of medical social work, social workers build a social support network that optimizes the recovery process of the client, so that the client can effectively obtain resources that can meet their own needs, so as to promote the full recovery of the client.

The basic hypothesis of social support network involved in rehabilitation work

The survival and development of human beings need to cooperate with others, 
and they also need the assistance of others. When members of society are in a state of pressure, in order to relieve this state of pressure and adverse effects, a series of resources need to be used. These resources include personal internal resources and external social support. The social support network of socially disadvantaged groups is relatively weak, and professional social workers are needed to help them build and optimize the social support network.

In real life, the group of patients with spine bending needs to receive longterm inpatient correction and rehabilitation treatment in the hospital, and the rehabilitation treatment process requires a lot of manpower and financial resources of the patient and his family. This puts the lives of patients and their families in a difficult situation, and also causes the group to be physically separated from the original interpersonal network for a certain period of time. During this period, they may always be in a state of lack of social connection. $\mathrm{Hu}$ man beings are social organisms with multiple levels of needs. During the physical isolation period of rehabilitation, patients with scoliosis will have a stronger need for psychological and social communication with others, and good social connections will also have a good role in promoting the rehabilitation of patients.

The mutual assistance network of social support network theory emphasizes the construction of autonomous groups. The so-called autonomous groups refer to a group of people who consciously define goals and join qualifications. Such groups often develop friends with common interests and provide mutual help to overcome common difficulties. Group members can obtain consultation and support in the group.

According to the social connection needs of patients with scoliosis in the rehabilitation process and the characteristics of mutual support, interpersonal interaction and psychological support among members in social support network theory. In the experiment, the team members used the reciprocal group model of group work to help the scoliosis patient group build an interpersonal assistance network between them, so as to optimize the rehabilitation system for scoliosis patients.

\section{The Implementation Process}

The experiment uses the group reciprocity model to carry out activities. It is believed that individuals have always been shaped in the environment and others have been shaping others, establishing a reciprocal support network between patients, treating the group as an organic whole, and coordinating the development of communication between the individual and the whole. Under the reciprocity model support system, group members find their self-worth in social belonging and interdependence, adjust their self-adaptive conditions, and better receive treatment.

The reciprocal group model believes in the abilities of the group members. By letting team members organize activities independently, they can carry out activities according to their own needs. Through the interaction between group 
members, it provides opportunities for group members to identify with each other, and provides opportunities for group members to express their individuality and share with others. In the activities, the concept of social workers helping others to help themselves is highlighted, so that the team members understand and support each other, achieve mutual assistance and openness, reach a consensus, obtain psychological support, solve problems, and adapt to the society.

\subsection{Needs Assessment}

The team conducted a needs assessment of potential team members in the early stage of the establishment, and mainly conducted questionnaire measurements, interviews and actual surveys on patients with scoliosis. The first is to investigate its general situation and understand its basic information including: gender, age, family status, education level, occupational status, economic status, etc. Afterwards, the patients were interviewed using the interview method. The main questions include: 1) What difficulties did you encounter during the recovery process? How to solve it? 2) How did you feel when you were sick? 3) Have you ever had a negative attitude towards the rehabilitation process? Why is there such an attitude? 4) What kind of help do you expect to receive during your hospital stay? 5) Are you willing to participate in the interaction with others? 6) What kind of activities are you more willing to participate in? Through interviews, social workers learned about the problems and needs faced by patients with scoliosis, and assessed the problems and needs so as to facilitate better group planning and provide professional services for them.

After investigation, it was found that patients with scoliosis mainly have three aspects of incompatibility: 1) Physiological maladaptation: Scoliosis patients feel unbearable during the rehabilitation process, and it is difficult to maintain and complete cardiopulmonary exercises in rehabilitation training. Scoliosis patients are difficult to fall asleep normally due to the obstacles of the treatment equipment, and easily collide when going up and down the elevator, causing inconvenience in life. 2) Psychological discomfort: The poor posture of scoliosis patients caused by the disease makes the patients prone to inferiority complex and sensitive, negative emotions are obvious. Patients who are newly admitted to the hospital are more likely to be anxious and worry about the effect of recovery due to their unsuitability. Some patients with scoliosis have a lack of interpersonal communication, poor social integration, and less communication with others. 3) Social inadaptability: Patients with scoliosis lack confidence in communicating with others due to their symptoms. Patients who have been treated for a long time tend to derail from other members of the society. Their peer group support system is weak and social pressure is high.

Through communication with patients with scoliosis, social workers found that the pressure in the rehabilitation process was greater. When establishing a group, social workers should pay more attention to the establishment of a sup- 
port system among group members to help group members relieve negative emotions, improve their psychological self-confidence and social integration, and help them adapt to the recovery process with the correct mentality.

\subsection{Experimental Process (Table 1)}

Table 1. Experimental process.

\begin{tabular}{|c|c|c|}
\hline Time & Place & Research/Activity Arrangement \\
\hline March & $\begin{array}{l}\text { Chengdu } \\
\text { Third } \\
\text { People's } \\
\text { Hospital }\end{array}$ & $\begin{array}{l}\text { 1. Talk to the patient to collect information, record the patient's basic information, pathology, and psychological } \\
\text { conditions, and select the group based on the evaluation of the patient's information, and determine the team } \\
\text { members. } \\
\text { 2. Conduct team member needs assessment. } \\
\text { 3. Designed to meet reciprocal group activities. } \\
\text { 4. Carry out activity preparation/arrangement. The activity will be carried out in three phases, April, May and June. } \\
\text { 5. Materials for preparatory activities. } \\
\text { 6. Carry out the division of labor among the staff and reconcile the interests of various stakeholders. } \\
\text { 7. Conduct activity evaluation. } \\
\text { 8. Conduct statistical analysis. } \\
\text { 9. Write research report }\end{array}$ \\
\hline
\end{tabular}

1. Training of team members

Inform the confidentiality principle of the experiment, joint participation, the restoration of social function, the identity of the team members, and the matters needing attention in the experiment.

2. Train the team leader's organization, planning, communication and coordination skills of reciprocal group members.

3. Inform the event schedule.

4. The first activity is to understand the basic information between the group members and establish the group relationship.

June-July

(Three groups carry out activities at the same time)

1. Reciprocity groups carry out activities

Precautions:

- Group leadership is in the hands of group members.

- The content of the activity is designed by the team members themselves.

- Social workers play a leading role.

2. The general group participates in routine activities of medical social workers

Precautions:

- Medical social workers act as leaders.

- The content of the event is designed by medical social workers.

3. The control group does not participate in any group activities

Precautions:

- Pay attention to the physical and psychological state of the team members to avoid imbalance.

4. Record of experiment process

5. Sorting out experimental data

6. Specific activity arrangements 


\begin{tabular}{|c|c|c|c|c|}
\hline & Process & Time & Specific activity & Aims \\
\hline & $\begin{array}{l}\text { Enrollment } \\
\text { ceremony }\end{array}$ & June 1 & $\begin{array}{l}\text { The social worker distributes the } \\
\text { companion group medal to the } \\
\text { group members. }\end{array}$ & $\begin{array}{l}\text { The group members know each other, and } \\
\text { inform the group members of the specific } \\
\text { arrangements and procedures of the overall } \\
\text { activity, ask the group members for their } \\
\text { opinions on the activity arrangements, and } \\
\text { emphasize the rules and principles of the } \\
\text { group activities to the group members. }\end{array}$ \\
\hline & Story sharing & June 7 & $\begin{array}{l}\text { 1. Treatment story. } \\
\text { 2. Accompanying and listening. }\end{array}$ & $\begin{array}{l}\text { Facilitate communication among group } \\
\text { members. }\end{array}$ \\
\hline & $\begin{array}{l}\text { Make a story } \\
\text { book }\end{array}$ & June 7-June 21 & $\begin{array}{l}\text { 1. Social workers collect stories } \\
\text { from patients with scoliosis in } \\
\text { the story sharing session. } \\
\text { 2. Collect group members' favorite } \\
\text { videos. }\end{array}$ & $\begin{array}{l}\text { Build a sense of belonging and } \\
\text { self-confidence. }\end{array}$ \\
\hline & Watch movie & June 27 & $\begin{array}{l}\text { Social work organizes patients } \\
\text { with scoliosis to learn easily. }\end{array}$ & $\begin{array}{l}\text { Icebreaking enhances contact between team } \\
\text { members. }\end{array}$ \\
\hline & Movie sharing & July 4 & $\begin{array}{l}\text { Share the feeling of watching a } \\
\text { movie. }\end{array}$ & $\begin{array}{l}\text { Enhancing member connections. } \\
\text { Strengthen daily life connections. }\end{array}$ \\
\hline & Concert & July 11 & Hold a theme concert. & $\begin{array}{l}\text { Facilitate collaboration among team } \\
\text { members. }\end{array}$ \\
\hline & $\begin{array}{l}\text { Activity video } \\
\text { clip }\end{array}$ & July 11-July 18 & Social work editing process. & Consolidate group member memories. \\
\hline & $\begin{array}{l}\text { Farewell } \\
\text { ceremony }\end{array}$ & July 24 & $\begin{array}{l}\text { Deal with the parting emotions of } \\
\text { group members. }\end{array}$ & Strengthen interpersonal connections \\
\hline August & $\begin{array}{l}\text { 1. Carry out data } \\
\text { 2. Evaluate the ef } \\
\text { 3. Write the expe }\end{array}$ & $\begin{array}{l}\text { orting and analys } \\
\text { ct of controlled t } \\
\text { ment report. }\end{array}$ & $\begin{array}{l}\text { is. } \\
\text { rials. }\end{array}$ & \\
\hline
\end{tabular}

\section{Group Evaluation}

The group uses questionnaire surveys, interviews and observations, and baseline comparative analysis to assess whether the group's goals have been achieved.

\subsection{Change in Relationship}

In the process of group activities, the relationship between social workers and group members has changed from unfamiliar to harmonious, and professional relations between social workers and group members are gradually established. Through interactive communication with the team members, the team members have a sense of trust and companionship to the social workers, so as to help the social workers better understand the team members' reality, problems and needs, so that they can make timely corrections and plans during the event.

In the group planning stage, social workers actively promote the group, recruit group members, and evaluate the problems and needs of the group members. In the development stage of group activities, social workers actively interact 
with group members, establish professional relationships, actively guide group members to play their roles, share emotions and experiences, coordinate group members' participation and exchanges, and observe the psychological changes of group members. At the end of the group, the social worker guides the group members to correctly handle the parting emotions, review the group activities, consolidate the effectiveness of the group, and make connections and preparations for the personal life after leaving.

\subsection{Relief of Stress}

In group activities, through the questionnaire survey, the use of baseline comparative analysis can see the improvement of the physical, psychological, and social pressures of the group members in the process of rehabilitation. Through the comparison before and after, it is found that in the process of group activities, the group members can share personal emotions, relieve psychological pressure, face physical pain and more intense rehabilitation training, and can also complete the matching and completion with the support and help of the group members. In the development of group activities, group members play a personal role, participate in interaction and communication to help them establish a sense of self-efficacy and social integration, and help them better alleviate social pressure.

\subsection{Establishment of Social Support System}

In the development of group activities, the group members shared their personal emotions and the recovery process, which aroused resonance and communication, further shortened the distance between the group members, helped them find their counterparts in the recovery process, and established a support system to face the treatment together. The establishment of a support system encourages and supports group members to better perform rehabilitation, helps group members to enhance their sense of belonging and reduces their sense of loneliness, and highlights the service effectiveness of group activities.

\section{Conflicts of Interest}

The authors declare no conflicts of interest regarding the publication of this paper.

\section{References}

Hou, H. Z., Chai, X. L., Li, Y. X., \& Cai, X. P. (2017). Research Progress in Nursing Care of Degenerative Scoliosis Surgery. Medical Journal of National Defending Forces in Northwest China, 38, 769-771.

Li, Y. L. (2019). The Effect of Psychological Intervention Combined with High-Quality Nursing on the Mental State and Medical Coping Styles of Patients with Idiopathic Scoliosis. Primary Medical Forum, 23, 4824-4825.

Ma, D. Q., Xie, X. D., Zhang, F. Y., Liu, R., \& Feng, L. (2016). Evidence-Based Nursing for the Prevention of Early Complications in Children with Neurofibroma and Scoliosis. 
Nursing Practice and Research, 13, 71-73.

Xue, S. W. (2019). Research on the Status Quo and Countermeasures of Medical Social Work Services Based on the Health Needs of Patients with Scoliosis in S Hospital. Jinan: Shandong University, 2019.

Zhao, F. N., Peng, H. J., Huo, L. T., \& Dong, Q. (2016). Survey on Anxiety and Related Factors in Patients with Scoliosis. Everyone's Health (Academic Edition), 10, 92-93.

Zhao, J. Q., \& Zeng, W. J. (2020). The Application of Rosenthal Effect Nursing Intervention in Patients with Scoliosis Surgery in Improving Patients' Self-Management Ability and Improving Their Negative Emotions. Medical Theory and Practice, 33, 135-137. 